\title{
BMJ Open Comparing neck extensor muscle function in asymptomatic Canadian adults and adults with tension-type headache: a cross-sectional study
}

\author{
Andrée-Anne Marchand, ${ }^{1}$ Mariève Houle, ${ }^{2}$ Marie-Pier Girard, ${ }^{2}$ Marie-Ève Hébert, ${ }^{3}$ \\ Martin Descarreaux ${ }^{2}$
}

To cite: Marchand A-A, Houle M, Girard M-P, et al. Comparing neck extensor muscle function in asymptomatic Canadian adults and adults with tensiontype headache: a crosssectional study. BMJ Open 2019;9:e020984. doi:10.1136/ bmjopen-2017-020984

Received 5 December 2017 Revised 4 April 2019 Accepted 15 April 2019
Check for updates

(c) Author(s) (or their employer(s)) 2019. Re-use permitted under CC BY-NC. No commercial re-use. See rights and permissions. Published by BMJ.

${ }^{1}$ Department of Anatomy, Université du Québec à TroisRivières, Trois-Rivières, Canada ${ }^{2}$ Department of Human Kinetics, Université du Québec à TroisRivières, Trois-Rivières, Canada ${ }^{3}$ Department of Medicine, Université de Montréal, Montréal, Canada

Correspondence to Dr Andrée-Anne Marchand; andree-anne.marchand@uqtr.ca

\section{ABSTRACT}

Aim To further the understanding of the pathophysiological mechanisms underlying tensiontype headache (TTH) by comparing the endurance and strength of neck extensor muscles under acute muscle fatigue in participants with TTH and asymptomatic participants.

Methods We conducted a cross-sectional analysis of neck extensor muscle performance. Asymptomatic participants and participants with TTH were recruited via social media platforms and from the Universite du Québec à Trois-Rivières community and employees. A total of 44 participants with TTH and 40 asymptomatic participants took part in an isometric neck extensor endurance task performed at $60 \%$ of their maximum voluntary contraction. Inclusion criteria for the headache group were to be older than 18 years old and to fulfil the International Headache Society classification's criteria for either frequent episodic or chronic TTH. Clinical (self-efficacy, anxiety, neck disability and kinesiophobia) and physical parameters (neck extensors maximum voluntary contraction, endurance time, muscle fatigue) as well as characteristics of headache episodes (intensity, frequency and associated disability) were collected for all participants. Surface electromyography was used to document upper trapezius, splenius capitis and sternocleidomastoids muscle activity and muscle fatigue.

Results Both groups displayed similar neck extensor muscle endurance capacity with a mean difference of $6.2 \mathrm{~s}(\mathrm{p}>0.05)$ in favour of the control group (control=68.1 $\pm 32.3 ; \mathrm{TTH}=61.9 \pm 20.1$ ). Similarly, participants in the headache group showed comparable neck extensor muscle strength $(95.9 \pm 30.4 \mathrm{~N})$ to the control group (111.3 $\pm 38.7 \mathrm{~N})$. Among participants with TTH, those scoring as severely incapacitated by headaches were the ones with higher neck-related disability $(F[1,44]=10.77 ; p=0.002)$, the more frequent headache episodes ( $F[1,44]=6.70 ; p=0.01$ ) and higher maximum headache intensity $(F[1,44]=10.81 ; p=0.002)$.

Conclusion A fatigue task consisting of isometric neck extension cannot efficiently differentiate participants with TTH from asymptomatic participants.
Strengths and limitations of this study

- Data related to severity and frequency of headache episodes were retrospectively self-reported based on episodes from the previous month.

- Surface electromyography was used to ensure and quantify muscle fatigue.

- Participants were mostly students and employees of the university community and the results may not be generalisable to different work environments.

- Eighty-four participants were included based on standardised diagnostic criteria.

\section{BACKGROUND}

Headache disorders are a common health issue, with more than $46 \%$ of the adult population suffering from active headache. ${ }^{1}$ Among all types, tension-type headache (TTH) is the most widespread type of headache worldwide with a global prevalence of $42 \% .^{2}$ On average, TTH develops in individuals of 25-30 years of age, its prevalence peaks between 30 and 39 years and affects women slightly more than men, with a prevalence ratio of 5:4. ${ }^{3}$ Risks factors to develop chronic tension-type headache $(\mathrm{CTTH})$ include analgesic medication overuse, depression, history of migraine and the presence of other pain syndromes. ${ }^{4}$ TTH is characterised by a pressing and tightening pain, of non-pulsating quality and bilateral location of symptoms of mild-to-moderate intensity with no or little aggravation of pain during physical activity. ${ }^{5}$ According to the International Headache Society (IHS), TTH can be further divided into three subcategories based on the frequency of episodes. Infrequent episodic headaches are characterised as occurring 1 day or less per month, the frequent episodic form corresponds to headaches occurring between 1 and 14 days per month for at least three consecutive months $(>12$ and $<180$ days per year) and the chronic form consists of 
15 days or more with headache per month (>180 days per year). ${ }^{235}$

Previous studies have shown that myofascial tissues are more sensitive in patients with TTH than in healthy patients and that such tenderness is correlated with TTH episode intensity and frequency. ${ }^{6-8}$ Similarly, nociceptive hypersensitivity has been reported at both cephalic and extracephalic locations in patients with CTTH. ${ }^{9}$ The clinical phenomenon of spread and pain referral for which pain is perceived as originating from a distant receptive field rather than the affected tissue is common in primary headaches. ${ }^{10} \mathrm{~A}$ mechanism that could explain this finding is the combination of convergence of trigeminal and cervical afferents on to neurons in the trigeminocervical complex of the brain stem, sensitisation of supraspinal neurons and decreased antinociceptive activity from supraspinal structures. ${ }^{10}{ }^{11} \mathrm{In}$ line with this concept, a study reported that of patients with TTH $88 \%$ had concomitant neck pain and that there was a significant correlation between the number of days with TTH and the number of days with neck pain in a year. ${ }^{12}$

Current evidence regarding musculoskeletal physical outcomes in TTH such as neck mobility and muscle strength is mixed. As such, Fernández-de-las-Peñas showed that patients with episodic tension-type headache (ETTH) or CTTH have less neck mobility than controls $^{13-15}$ while other authors reported no difference in global cervical ranges of motion between these two groups. ${ }^{14} 1617$ Similarly, TTH have been associated with shortening in muscle length ${ }^{18} 19$ and declined strength of the extensor muscles when progressing to the chronic form ${ }^{20}{ }^{21}$ while no difference between TTH and healthy participants has also been found. ${ }^{16}$ On the other hand, evidence both in favour ${ }^{20}$ and against ${ }^{16}{ }^{21}$ a decrease in flexion strength has been reported. Lastly, limited evidence is available regarding neck muscle endurance with one study reporting less neck flexor endurance in TTH compared with controls. ${ }^{22}$

Current evidence suggests that increased neck flexor isometric strength helps increase pressure pain threshold tolerance in CTTH. ${ }^{23}$ Furthermore, interventions aimed at the cervical region including massage, cervical strengthening, postural techniques, cervical mobilisation, progressive stretching or cervical relaxation exercises have shown to help reduce pain frequency, intensity and duration of headaches. ${ }^{24} \mathrm{On}$ the other hand, the role cervical extensor muscles play in the pathophysiological mechanism of TTH remains unclear, and the hypothesis that there is a relation between endurance and strength of these muscles and intensity and frequency of the TTH has not been explored thoroughly. To the best of our knowledge, this study is the first to investigate neck extensor muscle endurance in patients with TTH using electromyography (EMG) fatigue parameters, but also the first to explore such parameters in participants with TTH according to levels of headache-related disability.

\section{Aim}

This study aimed to compare endurance and strength of neck extensor muscles under acute muscle fatigue in participants with TTH and asymptomatic participants. It was hypothesised that overall, participants with TTH would have similar neck extensor strength and significantly lower neck extensor muscle endurance compared with controls. It was also hypothesised that subgroups of patients with higher levels of headache-related disability would present lower muscle strength and endurance.

Finally, potential correlations between physical variables related to the endurance task (muscle strength, endurance and muscular activity) and the clinical variables (anxiety, kinesiophobia, self-efficacy, neck and headache-related disability, neck pain and headache pain intensity) were explored.

\section{METHODS \\ Design}

The study was conducted at the Laboratory of Neuromechanics at the Université du Québec à Trois-Rivières (Canada). Recruitment and testing of participants went from August 2016 to July 2017.

\section{Patient and public involvement}

No patients or public members were involved in the research development process or the conduct of this study.

\section{Participants' selection}

A cross-sectional study was conducted for which 84 participants were conveniently recruited via social media platforms and from the university community and employees. Inclusion criteria for the headache group were to fulfil the IHS classification's criteria ${ }^{5}$ for either frequent ETTH or CTTH based on an estimated number of days with headaches each participant had over the last year (see table 1 for detailed classification criteria). Concomitance of neck pain and other types of headaches was allowed in the headache group as long as pain unrelated to TTH was not the dominant one. If participants fulfilled the IHS classification criteria for TTH but experienced only 12 episodes a year or less (classified as infrequent ETTH), they were allocated to the control group. Similarly, people not suffering from headache but still interested in participating in the research project were allocated to the control group if in addition they had no neck pain or had had less than three consecutive days of incapacitating neck pain over the last year.

Exclusion criteria included being under a course of treatment for headache or neck pain, having been diagnosed with fibromyalgia, having a recent history of cervical spine severe trauma, fracture, whiplash, medication overuse, infection, surgery or malignant lesion, and the presence of upper limb pain, neurological deficits or spasmodic torticollis. Pregnant women were excluded because of the prone position adopted during the experiment. All participants provided informed written consent prior to their entry in the study. 
Table 1 International Headache Society Classification criteria for frequent episodic and chronic tension-type headache ${ }^{5}$

\begin{tabular}{|c|c|}
\hline $\begin{array}{l}\text { Frequent episodic tension- } \\
\text { type headache }\end{array}$ & $\begin{array}{l}\text { Chronic tension-type } \\
\text { headache }\end{array}$ \\
\hline $\begin{array}{l}\text { A. At least } 10 \text { episodes } \\
\text { of headache occurring } \\
\text { on } 1-14 \text { days per month } \\
\text { on average for }>3 \text { months } \\
\text { ( } \geq 12 \text { and }<180 \text { days per year) } \\
\text { and fulfilling criteria B-D }\end{array}$ & $\begin{array}{l}\text { A. Headache occurring } \\
\text { on } \geq 15 \text { days per month } \\
\text { on average for }>3 \text { months } \\
\text { ( } \geq 180 \text { days per year) and } \\
\text { fulfilling criteria } B-D\end{array}$ \\
\hline $\begin{array}{l}\text { B. Lasting from } 30 \mathrm{~min} \text { to } \\
7 \text { days }\end{array}$ & $\begin{array}{l}\text { B. Lasting hours to days, or } \\
\text { unremitting }\end{array}$ \\
\hline $\begin{array}{l}\text { C. At least two of the } \\
\text { following four characteristics: } \\
\text { 1. bilateral location } \\
\text { 2. pressing or tightening } \\
\text { quality } \\
\text { (non-pulsating) } \\
\text { 3. mild or moderate intensity } \\
\text { 4. not aggravated by routine } \\
\text { physical activity such as } \\
\text { walking or climbing stairs }\end{array}$ & $\begin{array}{l}\text { C. At least two of the } \\
\text { following four characteristics: } \\
\text { 1. bilateral location } \\
\text { 2. pressing or tightening } \\
\text { quality } \\
\text { (non-pulsating) } \\
\text { 3. mild or moderate intensity } \\
\text { 4. not aggravated by routine } \\
\text { physical activity such as } \\
\text { walking or climbing stairs }\end{array}$ \\
\hline $\begin{array}{l}\text { D. Both of the following: } \\
\text { 1. no nausea or vomiting } \\
\text { 2. no more than one of } \\
\text { photophobia or phonophobia }\end{array}$ & $\begin{array}{l}\text { D. Both of the following: } \\
\text { 1. no more than one of } \\
\text { photophobia, phonophobia } \\
\text { or mild nausea } \\
\text { 2. neither moderate or severe } \\
\text { nausea nor vomiting }\end{array}$ \\
\hline
\end{tabular}

\section{Data collection}

\section{Clinical outcome measures}

The experimental session began with a history taking to obtain demographic data, information regarding typical episodes of headache and neck pain as well as the completion of validated questionnaires. Mean and maximum pain intensity over the last month for headache and neck pain was assessed using a Visual Analogue Scale (VAS). Disability was assessed using the 6-item Headache Impact Test (HIT-6) questionnaire for headaches ${ }^{25}$ and the Neck Disability Index (NDI) for neck pain. ${ }^{26}$ Kinesiophobia (Tampa Scale of Kinesiophobia), anxiety (State-Trait Anxiety Inventory (form Y) $)^{27}$ and self-efficacy ${ }^{28}$ were documented as potential factors that could explain the differences found between groups if any.

\section{Physical outcome measures}

Surface EMG (muscle activity)

Surface EMG data were collected bilaterally using bipolar surface electrodes applied over the midsection of the upper trapezius and splenius capitis muscles (at the vertebral level of C4) and parallel to the fibres orientation, as described by Criswell and Cram. ${ }^{29}$ Unwanted levels of cocontraction from the neck flexor muscles were monitored via the sternocleidomastoids (SCM) muscle activity. A ground electrode was placed over the left acromion. To avoid inter-rater variability, anatomical structures palpation and placement of electrodes were assessed by the same investigator for all participants. Skin impedance was reduced by shaving body hair, gently abrading the skin with fine-grade sandpaper (Red Dot Trace Prep, 3M, St. Paul, Minnesota, USA) and wiping the skin with alcohol swabs.

EMG activity was recorded using a single differential Delsys Surface EMG sensor with a common mode rejection ratio of $92 \mathrm{~dB}$ at $60 \mathrm{~Hz}$, a noise level of $1.2 \mu \mathrm{V}$, a gain of $10 \mathrm{~V} / \mathrm{V} \pm 1 \%$, an input impedance of $10^{15}$, a bandwidth of $20-450 \% \pm 10 \%$ (Model DE2.1, Delsys, Boston, Massachusetts, USA) and sampled at $2048 \mathrm{~Hz}$ with a 12-bit analogue-to-digital converter (PCI 6024E, National Instruments, Austin, Texas, USA). The EMG data were filtered digitally by a $10-450 \mathrm{~Hz}$ bandpass, zero-lag, and fifthorder Butterworth filter. Data were collected using the OT Bioelettronica custom software (OT Bioelettronica, Torino, Italy) and processed using Matlab (R2007b MathWorks, Natick, Massachusetts, USA).

\section{Neck extensor muscle maximum voluntary contraction}

Following skin preparation and electrodes placement, participants were asked to lay prone with the head and neck past the edge of the table. The cervicothoracic junction was stabilised to ensure minimal recruitment of scapular and thoracic muscles throughout the task. The strap length was then adjusted over the protuberantia occipitalis with the participant's head in a neutral horizontal position as depicted in figure 1 . One maximum voluntary contraction (MVC) trial was performed to allow participants to get familiar with the isometric extension contraction required during the endurance task and a further two trials were conducted afterwards. Participants were asked to slowly build up the force to maximal strength within $2 \mathrm{~s}$, and then exert maximal pressure for about $3 \mathrm{~s}$ and thereafter slowly relax. Participants were verbally encouraged to perform maximally. From the greater of the two contractions, the target force (and visual feedback) for the endurance task was set at $60 \%$ of the MVC deployed.

\section{Neck extensor muscle endurance task}

The feedback was displayed on a computer screen placed on the floor and for ease of identification the 1 bar graph became green when the target was reached or stayed red if under the target and became blue if over the $60 \%$ mark. Participants were instructed to maintain the neck extension for as long as possible and were verbally encouraged throughout the task. The test was stopped when participants mentioned that they were no longer able to maintain the position because of fatigue or when they were unable to maintain the head in a neutral horizontal position or if they failed to maintain within $\pm 5 \%$ from the $60 \%$ feedback mark on three occasions. Within seconds of the end of the endurance task, participants were asked to score their perceived level of effort using a Borg's Scale ${ }^{30}$ and to perform one last MVC. The development of any postexperimental headache was documented, and its intensity recorded using a numerical rating scale. 


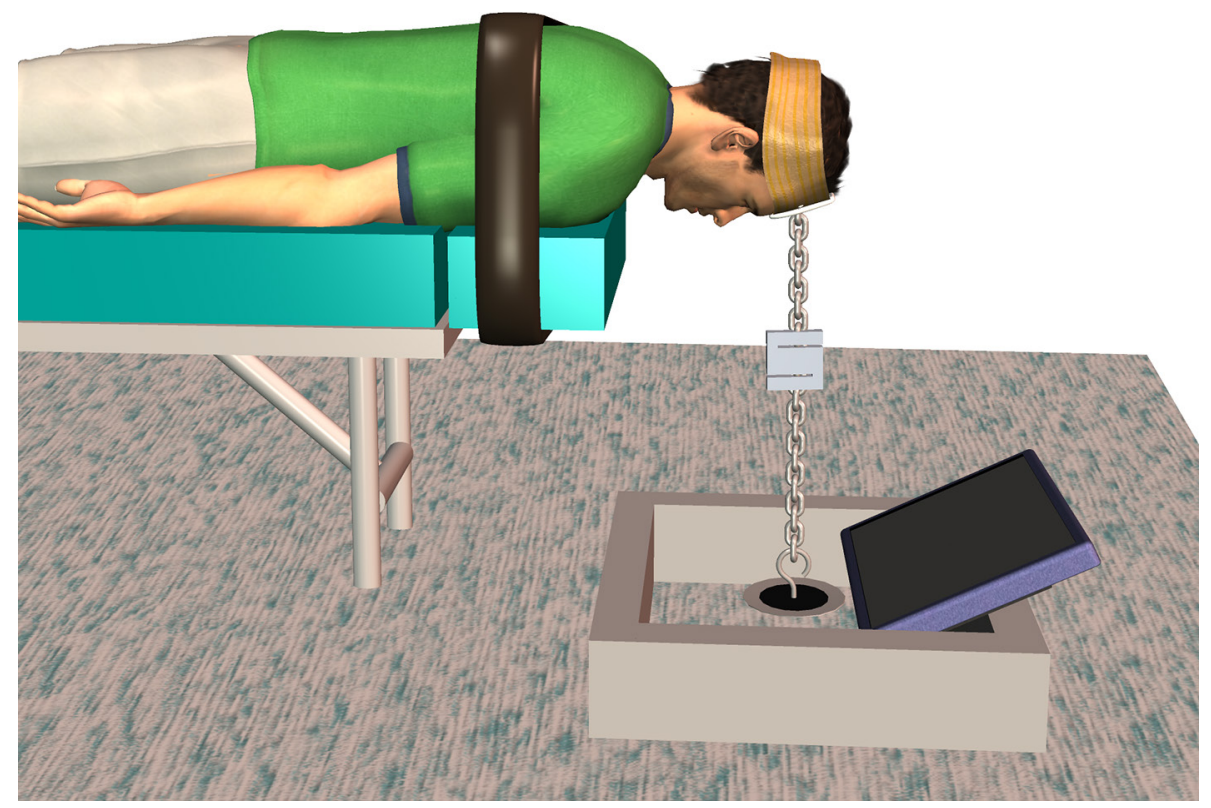

Figure 1 Isometric neck extensor muscles endurance test performed in the prone position with visual feedback.

\section{Data and statistical analyses}

Muscle fatigue was assessed using the pre-experiment and postexperiment (fatigue task) assessment differences in MVC. In addition, the root-mean-square (RMS) mean slope and the median frequency (MDF) mean slope were calculated from adjacent non-overlapping EMG signal epochs of $0.5 \mathrm{~s}$ for each muscle throughout the task.

Differences between groups were assessed using t-tests for independent samples. One-way analysis of c ovariances (ANCOVAs) were conducted to assess the difference between TTH and asymptomatic individuals on neck muscle extensor strength and endurance while controlling for sex. Physical and clinical outcomes of participants with TTH were compared based on their level of headache-related disability using one-way analysis of variances (ANOVAs). Correlations between physical (endurance time and MVC before the task) and clinical parameters (kinesiophobia, anxiety, self-efficacy, neck and headache-related disability, and pain frequency and intensity) were evaluated using Pearson's correlation coefficient. Analyses were performed using STATISTICA statistical package V.10 (Statsoft, Tulsa, Oklahoma, USA), and the level of significance was set at $\alpha=0.05$.

\section{RESULTS}

\section{Baseline demographics}

T-tests for independent samples confirmed that both groups were similar for age, height, weight and scores for the fear of movement, and self-efficacy questionnaires. However, the TTH group had a greater proportion of female participants $(72.9 \%)$ compared with the control group $(47.5 \%)$. In addition, the anxiety level differed between the groups with the participants with TTH ranking at low and the control group at minimal anxiety $(\mathrm{p}=0.03)$. The headache group included 44 participants and the control group 40. Reasons for participant exclusion are presented in figure 2.

Variables related to headache and neck pain differed between the two groups. Participants in the headache group had higher disability related to the presence of both headaches and neck pain, with the HIT-6 questionnaire (mean $\pm \mathrm{SD}=54.6 \pm 8.5$ for the TTH group; 42.6 \pm 5.6 for the control group) scoring at some disability on daily life functioning and the NDI (mean $\pm \mathrm{SD}=7.1 \pm 4.4$ for the TTH group; 2.0 \pm 2.7 for the control group) at mild disability. Similarly, headache intensity and frequency were higher in the headache group with a mean intensity of 4.6 on the VAS, which is considered moderate (1.9 for the control group), and a mean frequency of 8 episodes per month $(<1$ per month for the control group). Neck pain was also reported more frequently and of greater intensity in the headache group and although neck pain episodes were reported almost as frequently as headaches the intensity was rated lower than headache episodes with a mean score of 3.1 out of 10 , which is considered mild. ${ }^{31}$

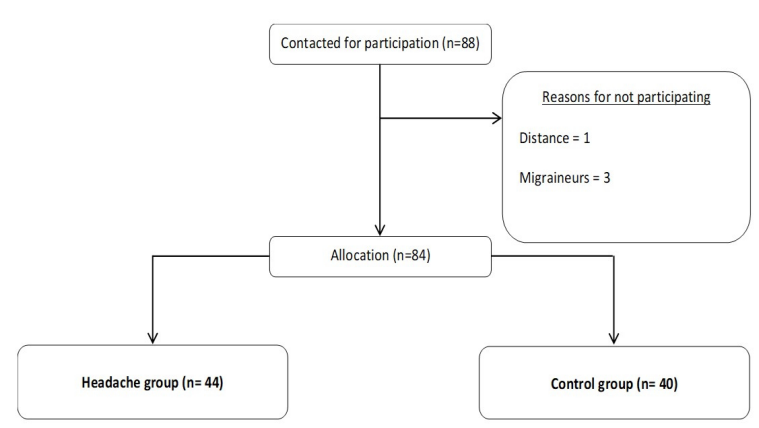

Figure 2 Flow chart of participants' enrolment and reasons for exclusion. 

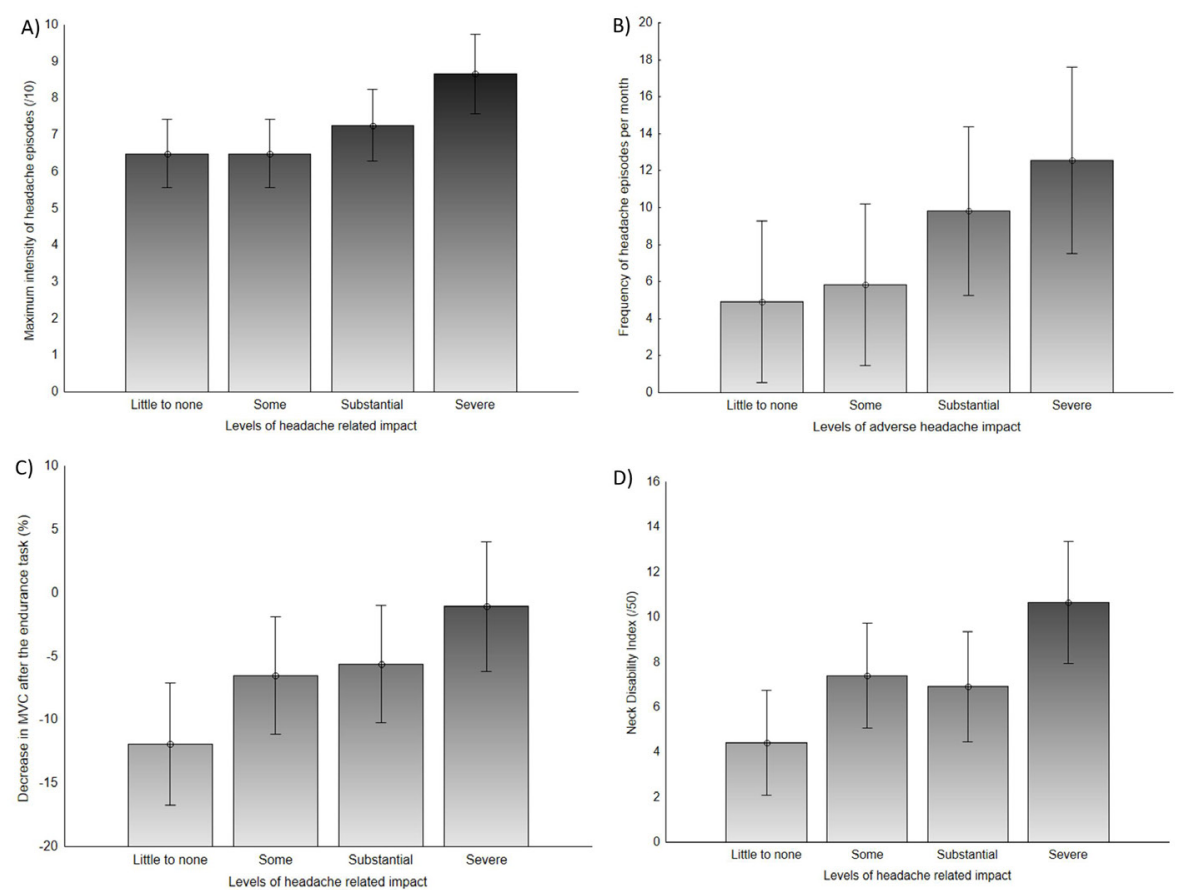

Figure 3 Clinical and physical outcomes by levels of headache-related disability as measured by the 6-item Headache Impact Test questionnaire. (A) Maximum intensity of headache episodes. (B) Frequency of headache episodes. (C) Decrease in maximum voluntary contraction (MVC) after the endurance task. (D) Neck-related incapacity.

\section{Endurance task}

One-way ANCOVA showed a significant effect of TTH on neck extension strength at the postfatigue measurement after controlling for $\operatorname{sex}\left(\mathrm{F}_{1,84}=134.7, \mathrm{p}<0.001\right)$ but not at baseline $\left(\mathrm{F}_{1,84}=0.14, \mathrm{p}=0.71\right)$. In addition, the difference in sex ratios between groups did not impact the time to fatigue in the endurance task $\left(\mathrm{F}_{1,84}=0.17\right.$, $\mathrm{p}=0.68)$. Fatigue occurred in all muscles with EMG data analysis showing a positive RMS slope, confirming the recruitment of additional motor units as the task went on (values ranging from 1109.8 up to $6245.9 \mathrm{~Hz} / \mathrm{s}, \mathrm{p}>0.05$ ). Fatigue was also confirmed in both groups by a mean negative MDF slope found for all muscles (values ranging from -0.11 up to $-0.30 \mathrm{~Hz} / \mathrm{s}, \mathrm{p}>0.05$ ). As it was expected, SCM muscles showed the least contribution during the endurance task as shown by their low levels of muscle fatigue (lowest among all measured muscles). The mean scores for the perceived amount of effort put into the task were slightly above 15 in both groups $(p>0.05)$. Finally, a $7 \%$ decrease in MVC was observed after the endurance task in the control group compared with $9 \%$ in the TTH group $\left(\mathrm{t}_{82}=0.5, \mathrm{p}=0.06\right)$ whereas the mean time for the endurance task was similar in both groups (mean difference $=6.2 \mathrm{~s}, \mathrm{p}>0.05)$. Greater headache $(\mathrm{r}=-0.29 ; \mathrm{p}=0.006)$ or neck-related disability $(\mathrm{r}=-0.24 ; \mathrm{p}=0.03)$, anxiety $(\mathrm{r}=-0.28 ; \mathrm{p}=0.01)$ and higher maximum headache pain intensity $(\mathrm{r}=-0.27 ; \mathrm{p}=0.01)$ were negatively correlated to the baseline MVC. Results for all clinical and physical variables are presented in table 2 .

\section{Performance of headache participants}

Participants with TTH were divided into levels of headache-related disability based on their score obtained on the HIT-6 questionnaire (minimum possible score is 36 and maximum possible score is 78). Categories are as followed; level 1 , little to no disability with score $\leq 49$; level 2 , some disability with score $=50-55$; level 3 , substantial disability with score $=56-59$; and level 4, severe disability with score $\geq 60$.

Comparing results of physical outcomes across levels of headache-related disability showed that individuals categorised into levels 1-3 behaved differently than those into the level 4. Results of clinical and physical parameters that differed based on the levels of headache-related disability are presented in table 3. Participants with severe headache-related disability produced a mean MVC 20.0\% lower (mean $\pm \mathrm{SD}=80.1 \mathrm{~N} \pm 19.4$ ) than the individuals in the other three categories (mean $\pm \mathrm{SD}=100.1 \mathrm{~N} \pm 32.3$ ). Similarly, participants scoring as severely incapacitated on the HIT-6 questionnaire were the ones with the smallest decrease in MVC after the endurance task $(\mathrm{F}[1,44]=9.40 ; \mathrm{p}=0.004)$, the higher neck-related disability $(\mathrm{F}[1,44]=10.77 ; \mathrm{p}=0.002)$, the more frequent headache episodes ( $\mathrm{F}[1,44]=6.70$; $\mathrm{p}=0.01$ ) and the higher maximum headache intensity $(\mathrm{F}[1,44]=10.81 ; \mathrm{p}=0.002)$. Among the physical and clinical outcomes, lower baseline MVC $(r=0.43, \mathrm{p}=0.05)$, neck pain-related disability $(\mathrm{r}=0.47, \mathrm{p}=0.02)$, frequency of headache episodes $(\mathrm{r}=0.42, \mathrm{p}=0.05)$ and maximum intensity of headache episodes $(\mathrm{r}=0.45, \mathrm{p}=0.03)$ were moderately but significantly correlated with HIT-6 scores. 
Table 2 Participants' results for clinical and physical variables

\begin{tabular}{|c|c|c|c|c|}
\hline & Variables & $\begin{array}{l}\text { Control group }(n=40) \\
\text { Mean } \pm S D\end{array}$ & $\begin{array}{l}\text { Headache group } \\
(n=44) \\
\text { Mean } \pm \text { SD }\end{array}$ & $P$ value \\
\hline \multirow[t]{8}{*}{ Demographics } & Age (years) & $29.8 \pm 10.9$ & $27.6 \pm 10.3$ & 0.34 \\
\hline & $\mathrm{F}: M$ & $19: 21$ & $32: 12$ & $0.01^{*}$ \\
\hline & Years w/headache & $0.8 \pm 3.9$ & $10.7 \pm 8.7$ & $<0.001^{*}$ \\
\hline & Weight (kg) & $72.3 \pm 15.5$ & $67.4 \pm 11.5$ & 0.10 \\
\hline & $\mathrm{IMC}\left(\mathrm{kg} / \mathrm{m}^{2}\right)$ & $24.5 \pm 4.0$ & $24.1 \pm 3.9$ & 0.64 \\
\hline & Kinesiophobia (17-68) & $26.8 \pm 6.1$ & $28.5 \pm 6.2$ & 0.20 \\
\hline & Self-efficacy (10-40) & $35.8 \pm 0.3 .9$ & $34.7 \pm 3.6$ & 0.18 \\
\hline & Anxiety (20-80) & $33.1 \pm 10.6$ & $38.0 \pm 10.2$ & $0.03^{*}$ \\
\hline Headache & HIT-6 (36-78) & $42.6 \pm 5.6$ & $54.6 \pm 8.5$ & $<0.001^{\star}$ \\
\hline \multirow[t]{5}{*}{ Neck pain } & Frequency (per month) & $2.7 \pm 6.3$ & $7.2 \pm 9.2$ & $0.01^{*}$ \\
\hline & Mean intensity (/10) & $1.6 \pm 1.4$ & $3.1 \pm 1.7$ & $<0.001^{*}$ \\
\hline & $\begin{array}{l}\text { Maximum intensity } \\
(/ 10)\end{array}$ & $2.6 \pm 2.3$ & $4.6 \pm 2.3$ & $<0.001^{*}$ \\
\hline & NDI (/50) (\%) & $2.0 \pm 2.7(4.0)$ & $7.1 \pm 4.4(14.2)$ & $<0.001^{*}$ \\
\hline & NDI (/45)† (\%) & $1.5 \pm 2.6(3.3)$ & $5.0 \pm 4.4(11.1)$ & $<0.001^{*}$ \\
\hline Endurance task & MVC before $(\mathrm{N})$ & $111.3 \pm 38.7$ & $95.9 \pm 30.4$ & $0.04^{*}$ \\
\hline
\end{tabular}

*Statistically significant difference.

$\dagger$ Neck Disability Index (NDI) score calculated without the headache question (item 5).

F, female; HIT-6, 6-item Headache Impact Test; IMC, body mass index; M, male; MVC, maximum voluntary contraction.

Table 3 Results of physical and clinical parameters that differ between levels of headache-related disability as measured by the 6-item Headache Impact Test questionnaire

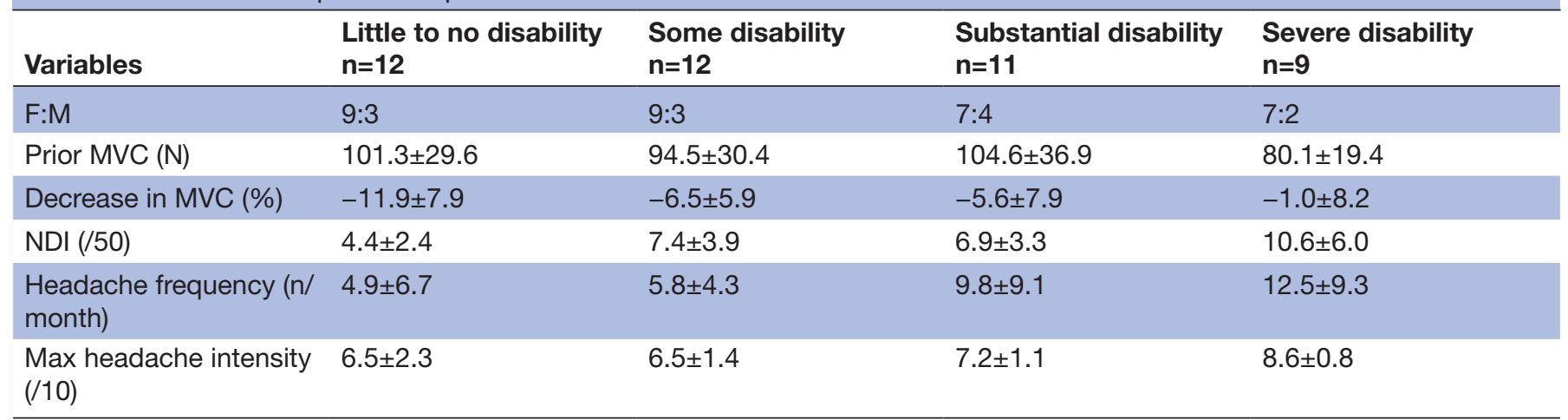

F, female; M, male; MVC, maximum voluntary contraction; NDI, NeckDisability Index. 


\section{DISCUSSION}

The purpose of this study was to compare endurance and strength of neck extensor muscles under acute muscle fatigue in individuals with TTH and asymptomatic participants. The results showed that participants with TTH had similar endurance (length of task), rate of muscle fatigue (EMG RMS and MDF mean slopes) and isometric strength in extension compared with asymptomatic participants.

The current research protocol was based on the premise that TTH and neck pain are, from a physiological and clinical standpoint, intricately linked. The development of chronic neck pain has been previously associated with changes in neck muscle endurance with recent evidence suggesting a decreased resistance to fatigue ranging from $21 \%$ to $76 \%$ in patients with neck pain compared with controls. ${ }^{32-34}$ Our results combined with previously published evidence do not support this observation in participants with TTH.

However, Madsen et al reported that concomitance of neck tenderness in patients with TTH has a negative influence on force production which could be explained by a modulation of muscle activity aimed at avoiding painful experiences characterised by an increased activity in antagonist muscles and a decreased activity in agonist muscles. ${ }^{35}$ An imbalance in force production between the neck flexor and extensor muscles has also been considered a potential contributing factor of CTTH development. As such, Madsen et al reported a 12\% decrease in neck extension/flexion strength ratio in the TTH population ${ }^{36}$ and a $26 \%$ difference in extension strength between TTH and healthy subjects. ${ }^{21}$ In addition, patients with TTH have been found to have significantly lower neck extension force steadiness compared with healthy controls. ${ }^{35}$ Even though in our study those with severe headache-related disability showed a significantly reduced force production, the TTH group as a whole did not show a significant difference in neck extensor force compared with the control group. Indeed, the proportion of participants belonging to each headache-related disability subgroups may very well explain the conflicting results observed across studies with regard to neck muscle function in patients with TTH.

Interestingly, individuals with severe headache-related disability had the lowest decrease in MVC post experiment. Although surprising, this observation could be explained by high levels of pericranial tenderness expected in those with greater headache frequency and intensity, which could have influenced their performance given the nature of the experimental setting. Although the strap on which participants exerted pressure while performing the extension task was padded to avoid discomfort, and that no participants reported such discomfort, it cannot be excluded that pain or discomfort during the task may have played a role in participants' performance.

In addition, muscular fibre type changes have been hypothesised as an adaptive response to conditions such as injuries, presence of pain, nerve pathology or inflammatory processes ${ }^{37}$ and have been reported in $\mathrm{TTH}^{38}$
Fibre-type conversion is characterised by an increase in the proportion of slow twitch fibres which in turn led to a reduction in MVC amplitude in headache sufferers. ${ }^{38}$ Modification to muscular fibres distribution, characterised by an increased number of intermediate fibres (type IIC), occurs in subsequent stages (from either slow twitch or fast twitch fibres) and is believed to start within the first year of symptoms onset and terminate 1 to 2 years later. ${ }^{39}$ The combination of data obtained from surface EMG for muscle fatigue (RMS and MDF mean slopes) and the endurance time which was similar in both our TTH and asymptomatic participants suggests that there is no morphological difference in neck extensor muscle fibre types between the two groups. These results are in accordance with the findings from the study by Biyouki $e t$ $a l$ which reported minimal differences in muscle activity between CTTH and controls at rest. ${ }^{40}$

The absence of a clear cervical musculoskeletal impairment in the majority of subjects tested in this study revives the debate around the hypothesis that neck pain may be part of TTH pain pattern, rather than reflecting a local cause in the cervical spine. Although central sensitisation pathways and the afferents from the trigeminocervical complex ${ }^{1011}$ have both been identified as possible mechanisms underlying pain pattern presentation in headaches, uncertainty persists around the nature of the role played by neck pain, if any, in TTH presentation. ${ }^{41}$ Despite the lack of association between neck muscular dysfunction and clinical portrait found in the present study, future studies should aim to identify a core set of outcome measures, similar to the one developed in patients with migraine, ${ }^{42}$ to help clarify the origin or cause of neck pain in TTH.

\section{Performance of participants with headache}

Another aim of this study was to compare the results of the participants with TTH based on the four levels of headache-related disability (from the HIT-6). Among headache sufferers, those with 'high headache-related disability' produced less maximum neck extensor force and lost minimal strength during the fatigue task than those in the 'little to no disability' to the 'substantial headache-related disability' categories. In addition, participants scoring at high levels of headache-related disability had greater neck-related disability, reported greater pain severity and suffered from headache more frequently than their counterparts. Overall, participants in the lower three categories of headache-related disability did not behave differently than the control group. These findings suggest that patients with severe headache incapacity display physiological changes that may be influenced by other biological or associated psychological factors that were not captured in the present study or that may be triggered as the condition progresses to a more chronic stage.

\section{Limitations}

This study is not without limitations. Data related to severity and frequency of headache episodes were 
self-reported based on episodes from the previous month, which may be subject to recollection bias. A prospective data collection would have allowed for a more precise estimate of these clinical variables. In addition, the testing apparatus provided information regarding neck extensor muscle strength and endurance from a prone position, and considering that most waking hours are spent upright, the task may not be fully representative of the daily complex neck muscle interactions and postures. Similarly, the characterisation of the chosen neck muscles as purely extensors may not exactly reflect the function of these muscles and does not take into consideration their stabilising role which again may be different in bearing and non-weight-bearing positions. Furthermore, an interim sample size calculation was conducted to ensure sufficient power to detect differences between the TTH and asymptomatic participants, but the uneven and small number of participants included in the ANOVAs for the four subcategories from the HIT-6 is likely to be underpowered and therefore the results of this analysis should be interpreted with caution.

\section{CONCLUSION}

The results from the present study indicate that a fatigue task consisting of isometric neck extension cannot efficiently differentiate participants with TTH from controls. In addition, parameters related to neck extensor muscles fatigability are not correlated with the severity of headache symptoms. Furthermore, force production may only be associated with symptomatology of patients that are categorised with high level of headache-related incapacity. Future studies should further investigate the relationship between levels of headache-related disability and physiological changes.

Contributors AAM and MD: research area and study design; AAM, MH, MPG and MEH: data acquisition; AAM, MH and MD: data analysis and interpretation; AAM and MD: statistical analysis; MD: supervision and mentorship. AAM, MH, MEH and MPG: manuscript writing. MD takes responsibility that this study was been reported, transparently and honestly.

Funding The authors have not declared a specific grant for this research from any funding agency in the public, commercial or not-for-profit sectors.

Competing interests None declared.

Ethics approval This study has been approved by the ethic committee of human subjects of the Université du Québec à Trois-Rivières (CER-16-225-07.15).

Provenance and peer review Not commissioned; externally peer reviewed. Data sharing statement № additional data are available.

Open access This is an open access article distributed in accordance with the Creative Commons Attribution Non Commercial (CC BY-NC 4.0) license, which permits others to distribute, remix, adapt, build upon this work non-commercially, and license their derivative works on different terms, provided the original work is properly cited, appropriate credit is given, any changes made indicated, and the use is non-commercial. See: http://creativecommons.org/licenses/by-nc/4.0/.

\section{REFERENCES}

1. Stovner L, Hagen K, Jensen R, et al. The global burden of headache: a documentation of headache prevalence and disability worldwide. Cephalalgia 2007;27:193-210.
2. Palacios Ceña M, Castaldo M, Wang K, et al. Topographical pressure pain sensitivity maps of the temporalis muscle in people with frequent episodic and chronic tension-type headache. Pain Pract 2017:17:1050-7.

3. Jensen $\mathrm{RH}$. Tension-type headache - the normal and most prevalent headache. Headache 2018;58:339-45.

4. Crystal SC, Robbins MS. Epidemiology of tension-type headache. Curr Pain Headache Rep 2010;14:449-54.

5. Headache Classification Committee of the International Headache Society (IHS). The international classification of headache disorders, 3rd edition (beta version). Cephalalgia 2013;33:629-808.

6. Lipchik GL, Holroyd KA, O'Donnell FJ, et al. Exteroceptive suppression periods and pericranial muscle tenderness in chronic tension-type headache: effects of psychopathology, chronicity and disability. Cephalalgia 2000;20:638-46.

7. Bendtsen L, Ashina S, Moore A, et al. Muscles and their role in episodic tension-type headache: implications for treatment. Eur $J$ Pain 2016;20:166-75.

8. Bendtsen L, Fernández-de-la-Peñas $C$. The role of muscles in tension-type headache. Curr Pain Headache Rep 2011;15:451-8.

9. Bendtsen L, Jensen R. Tension-Type Headache. Neurol Clin 2009;27:525-35.

10. Bartsch T, Goadsby PJ. The trigeminocervical complex and migraine: current concepts and synthesis. Curr Pain Headache Rep 2003;7:371-6.

11. Bendtsen L. Central sensitization in tension-type headache--possible pathophysiological mechanisms. Cephalalgia 2000;20:486-508.

12. Ashina S, Bendtsen L, Lyngberg AC, et al. Prevalence of neck pain in migraine and tension-type headache: a population study. Cephalalgia 2015;35:211-9.

13. Fernández-de-las-Peñas $C$, Alonso-Blanco $C$, Cuadrado $M L$, et al. Forward head posture and neck mobility in chronic tension-type headache: a blinded, controlled study. Cephalalgia 2006;26:314-9.

14. Sohn JH, Choi HC, Lee SM, et al. Differences in cervical musculoskeletal impairment between episodic and chronic tensiontype headache. Cephalalgia 2010;30:1514-23.

15. Fernández-de-Las-Peñas C, Cuadrado ML, Pareja JA. Myofascial trigger points, neck mobility, and forward head posture in episodic tension-type headache. Headache 2007;47:662-72.

16. Jull G, Amiri M, Bullock-Saxton J, et al. Cervical musculoskeletal impairment in frequent intermittent headache. Part 1: Subjects with single headaches. Cephalalgia 2007;27:793-802.

17. Zwart JA. Neck mobility in different headache disorders. Headache 1997;37:6-11.

18. Fernández-de-las-Peñas $\mathrm{C}$, Alonso-Blanco $\mathrm{C}$, Cuadrado $\mathrm{ML}$, et al. Trigger points in the suboccipital muscles and forward head posture in tension-type headache. Headache 2006;46:454-60.

19. Fernandez-de-las-Peñas $C$, Pérez-de-Heredia M, Molero-Sánchez $A$, et al. Performance of the craniocervical flexion test, forward head posture, and headache clinical parameters in patients with chronic tension-type headache: a pilot study. J Orthop Sports Phys Ther 2007:37:33-9.

20. Fernández-de-las-Peñas C, Falla D, Arendt-Nielsen L, et al. Cervical muscle co-activation in isometric contractions is enhanced in chronic tension-type headache patients. Cephalalgia 2008;28:744-51.

21. Madsen BK, Søgaard K, Andersen LL, et al. Neck and shoulder muscle strength in patients with tension-type headache: A casecontrol study. Cephalalgia 2016;36:29-36.

22. Sohn JH, Choi HC, Jun AY. Differential patterns of muscle modification in women with episodic and chronic tension-type headache revealed using surface electromyographic analysis. $J$ Electromyogr Kinesiol 2013;23:110-7.

23. Castien R, Blankenstein A, De Hertogh W. Pressure pain and isometric strength of neck flexors are related in chronic tension-type headache. Pain Physician 2015;18:E201-5.

24. Espí-López GV, Arnal-Gómez A, Arbós-Berenguer T, et al. Effectiveness of physical therapy in patients with tension-type headache: Literature review. J Jpn Phys Ther Assoc 2014;17:31-8.

25. Magnoux E, Freeman MA, Zlotnik G. MIDAS and HIT-6 French translation: reliability and correlation between tests. Cephalalgia 2008;28:26-34.

26. Wlodyka-Demaille S, Poiraudeau S, Catanzariti JF, et al. French translation and validation of 3 functional disability scales for neck pain. Arch Phys Med Rehabil 2002;83:376-82.

27. Gauthier JBS. Adaptation canadienne française de la forme révisée du state trait anxiety inventory de spielberger. Rev Can Sci Comport 1993;25:559-78.

28. Scholz U, Gutiérrez-Doña B, Sud S, et al. Is general self-efficacy a universal construct? Psychometric Findings from 25 Countries 2002.

29. Criswell E, Cram JR. Cram's introduction to surface electromyography. Sudbury, MA: Jones and Bartlett, 2011. 
30. BORG GAV. Psychophysical bases of perceived exertion. Medicine \& Science in Sports \& Exercise 1982;14:377???381-81.

31. Jensen MP, Chen C, Brugger AM. Interpretation of visual analog scale ratings and change scores: a reanalysis of two clinical trials of postoperative pain. J Pain 2003;4:407-14.

32. Lee H, Nicholson LL, Adams RD. Neck muscle endurance, selfreport, and range of motion data from subjects with treated and untreated neck pain. J Manipulative Physiol Ther 2005;28:25-32.

33. Peolsson A, Kjellman G. Neck muscle endurance in nonspecific patients with neck pain and in patients after anterior cervical decompression and fusion. $J$ Manipulative Physiol Ther 2007;30:343-50.

34. Kahlaee AH, Rezasoltani A, Ghamkhar L. Is the clinical cervical extensor endurance test capable of differentiating the local and global muscles? Spine $J$ 2017;17:913-21.

35. Madsen BK, Søgaard K, Andersen LL, et al. Neck/shoulder function in tension-type headache patients and the effect of strength training $J$ Pain Res 2018;11:445-54.
36. Madsen BK, Søgaard K, Andersen LL, et al. Efficacy of strength training on tension-type headache: A randomised controlled study. Cephalalgia 2018;38:1071-80.

37. O'Leary S, Falla D, Elliott JM, et al. Muscle dysfunction in cervical spine pain: implications for assessment and management. J Orthop Sports Phys Ther 2009;39:324-33.

38. Jensen R, Fuglsang-Frederiksen A, Olesen J. Quantitative surface EMG of pericranial muscles in headache. A population study. Electroencephalogr Clin Neurophysiol 1994;93:335-44.

39. Weber BR, Uhlig Y, Grob D, et al. Duration of pain and muscular adaptations in patients with dysfunction of the cervical spine. $J$ Orthop Res 1993;11:805-10.

40. Biyouki F, Laimi K, Rahati S, et al. Morphology of muscular function in chronic tension-type headache: a pilot study. Acta Neurol Belg 2016;116:317-24.

41. Jull G, Hall T. Cervical musculoskeletal dysfunction in headache: How should it be defined? Musculoskelet Sci Pract 2018;38:148-50.

42. Luedtke K, Starke W, May A. Musculoskeletal dysfunction in migraine patients. Cephalalgia 2018;38:865-75. 